\title{
Raça e Origem dos presidiários africanos como possíveis agravantes para as decisões judiciais: Uma análise do Perfil dos presidiários estrangeiros no Estado do Rio de Janeiro.
} Eleutério Lúcio Rogério Nhantumbo

\section{Resumo}

O presente artigo apresenta uma análise do perfil dos presidiários estrangeiros, com vista a estudar o tratamento dado, aos presos estrangeiros africanos em comparação com os estrangeiros não africanos e brasileiros, pelo sistema de justiça do Estado do Rio de Janeiro, tendo em consideração as possibilidades de existência de tratamento discriminatório na atribuição da pena.

Palavras Chave: Estrangeiro, Prisão, Viés Racial, Sistema de Justiça.

\begin{abstract}
This paper presents an analysis of the profile of foreign prisoners, in order to study the treatment the treatment given to African foreign prisoners compared to non-African foreigners and Brazilians, from the justice system of the State of Rio de Janeiro, taking into account the possibilities of discriminatory treatment in the allocation of punishment.
\end{abstract}

Keywords: Foreign, Imprisonment, Bias Racial, Justice System.

\section{INTRODUÇÃO}

O presente artigo expõem análises preliminares apresentadas no meu projeto de qualificação do mestrado, ainda em andamento. Neste contexto, proponho fazer uma abordagem sobre o tratamento dado aos estrangeiros africanos presos e condenados no sistema penitenciário do Estado do Rio de Janeiro. Ainda nesta fase de estudo, a análise apresentada possuí maior enfoque apenas no perfil desses presos, em relação ao tratamento dado pelo sistema de justiça criminal tendo em consideração a possibilidade de existência de viés racial ou outro tratamento discriminatório pretendo apresentar depois da conclusão da minha dissertação de mestrado. 
Para fazer esta análise comparei os perfis dos presos (sexo, cor, estado civil, escolaridade e tipo de crime). Também verifiquei quais eram os crimes mais cometidos pelos africanos (negros), brasileiros e os estrangeiros não africanos. E posteriormente pretendo comparar a extensão das penas em relação aos crimes cometidos pelos africanos, em relação a outras nacionalidades e; estudar, qual é o tratamento jurídico dado pelo Sistema de Justiça Penal brasileiro, em termos de benefícios de liberdade provisória para além de outros benefícios, para os africanos em relação aos brasileiros e outras nacionalidades.

Do ponto de vista metodológico, para além do levantamento bibliográfico e de legislação existente sobre o estrangeiro, inicialmente, recorri à análise estatística dos dados que constam na base de dados fornecida em 2007 pelo Sistema de Informações Penitenciárias (SIPEN) da Vara de Execuções Penais do Rio de Janeiro (VEP). Este sistema armazena dados estatísticos e informações de todos os condenados e de todos os processos tombados na VEP desde 1996, data de sua criação.

O meu interesse em fazer esta abordagem se centra na demanda atual que tem imposto aos dirigentes políticos de diversos países, a criação de um equilíbrio adequado entre os interesses de segurança dos Estados e os direitos humanos dos imigrantes. Constata-se que grande parte dos povos imigrantes estrangeiros abandona os seus países de origem à procura de uma vida digna, uma vez que a maioria dessas deslocações está associada a várias causas, por exemplo, a guerras, ditaduras, distribuição injusta da riqueza, desintegração dos Estados e violação dos direitos humanos ${ }^{1}$. Contudo, estes cenários que levam a imigração, também podem trazer como consequência o envolvimento dos imigrantes estrangeiros no mundo do crime nos países acolhedores, na busca uma forma de satisfazer as suas necessidades básicas.

Entretanto olhando para a situação do imigrante estrangeiro no Brasil, segundo a última contagem da população realizada pelo $\mathrm{IBGE}^{2}$, concluiu-se que em 1996 já residiam no Brasil 103.078 estrangeiros, dos quais 53,5\% do sexo masculino. Mesmo assim, segundo o IBGE, estes dados não são confiáveis e precisos, visto que uma grande parcela dos estrangeiros no Brasil encontra-se em situação ilegal.

Por outro lado, interrogo se devido à situação ilegal de certos imigrantes no Brasil assim como a estada de estrangeiros no Brasil com a sua situação legalizada, tem criado manifestações nas sociedades que os culpam de praticas de alguns crimes como, por exemplo, o tráfico internacional de drogas. Estes questionamentos nos fazem por sua vez também interrogar se os estrangeiros que cometeram tais delitos influenciam o aumento da

\footnotetext{
${ }^{1}$ Disponível em: http://www.portalbrasil.net/brasil_populacao.htm, acesso em 29/03/1.

${ }^{2}$ Idem.
} 
população carcerária brasileira, visto que no ano de 2010, o Conselho Nacional de Justiça Brasileiro $(\mathrm{CNJ})^{3}$ concluiu que o Brasil possuía a terceira maior população carcerária de todo o mundo, com 494.598 presos, antecedido pelos Estados Unidos, que tem 2.297.400 presos, e da China, com 1.620.000 encarcerados.

Portanto, dentro destes questionamentos, proponho direcionar a minha análise ao tratamento dado aos presos estrangeiros africanos no estado do Rio de Janeiro, tendo em consideração na possibilidade de existência do viés racial. Uma vez que a descriminação racial no Brasil tem antecedentes históricos importantes, tendo aumentado durante o século XIX na relação entre estrangeiros imigrantes europeus brancos e nativos pretos e mulatos (Fernandes, 1965). Segundo Carlos Hasenbalg (1979) e Nelson do Valle e Silva (1988 e 1992), que fizeram estudos das relações raciais no Brasil contemporâneo, a discriminação se devia a diversas práticas racistas presentes na sociedade brasileira mesmo depois da abolição da escravatura.

Atualmente, o contexto da imigração estrangeira no Brasil é diferente em relação ao período anterior à abolição da escravatura. Uma parte dos imigrantes é temporária ou trabalhadores de mão-de-obra qualificada e de classe média, originários de países desenvolvidos, geralmente empresários, executivos, técnicos e funcionários de empresas multinacionais. Segundo o Ministério do Trabalho ${ }^{4}$, em 1999 foram concedidas 12.708 autorizações a trabalhadores estrangeiros, dos quais 17,26\% eram americanos, 9,54\%, ingleses e 6,15\%, alemães. Em geral, esses trabalhadores permanecem no país por um período máximo de três anos. São raros os casos em que fixam residência definitiva.

Os imigrantes de residência permanente, que na sua maioria é pobre e carente, se dirigem para os centros urbanos mais desenvolvidos, principalmente São Paulo e Rio de Janeiro. E grande parte dessa população não possui documentação necessária para sua legalização, sujeitando-se a péssimas condições de vida, habitando pequenos cômodos coletivos, além de serem obrigados a trabalhar até 16 horas por dia em troca de dois a três salários mínimos por mês. (Assis, 2002)

Portanto, associando as possibilidades de existência de preconceito ao estrangeiro, em geral, aos indivíduos de cor escura (pretos e mulatos) em especial, embora a constituição

\footnotetext{
${ }^{3}$ Disponível em: http://www.cnj.jus.br, acesso em 27/03/11. Segundo o CNJ, nos últimos cinco anos o número de presos no Brasil aumentou em 37\%, o que representa 133.196 pessoas a mais no sistema penitenciário. Ainda, 44\% dos presos são provisórios, significando um numero de 219.274 pessoas aguardando na prisão o julgamento de seus processos.

${ }^{4}$ Disponível em: http://www.portalbrasil.net/brasil_populacao.htm, acesso em 29/03/11.
} 
federal brasileira preveja o tratamento igual para todos, podemos questionar também a penalização e as decisões dos tribunais para com os mesmos.

Estas questões têm validade, visto que vários estudos feitos no Brasil, [(Hasenbalg (1979) e Do Valle e Silva (1988 e 1992)], concluíram que no passado os pobres e pretos eram os mais propensos ao crime do que os ricos brancos, o que é um erro grave. Os funcionários jurídico-policiais pareciam acreditar nisto, e tratavam com mais severidade quem não fosse branco. Ainda segundo alguns pesquisadores, como Costa Ribeiro (1995), a situação dos julgamentos no início do século XX não era apenas uma curiosidade histórica, as doutrinas do direito clássico e da Escola Positiva de Direito Penal permanecem, de forma um pouco modificada, no código penal brasileiro, e a discriminação racial continua operando na sociedade brasileira.

Constatava-se que os homens de cor branca e os acusados de crimes contra pretos ou pardos tinham mais chance de absolvição do que qualquer outro tipo de indivíduo. Havia discriminação racial em alguns julgamentos no tribunal de júri, visto que a ideia dominante na sociedade brasileira do início do século XX era de que os pretos e os pardos eram indivíduos inferiores, o que conduzia a julgamentos discriminatórios. (Costa Ribeiro, 1995)

Por forma a debater melhor sobre a problemática do viés racial n o sistema de justiça criminal, importa lembrar que este sistema no Brasil inicia o seu funcionamento com a atuação policial (Militar e Civil), de seguida do Ministério Público, judiciário e termina no sistema carcerário (Ribeiro, 2009). No Brasil existem poucos estudos que debatem a problemática do viés racial no funcionamento do sistema de justiça criminal, e das poucas pesquisas existentes no Brasil que estudam esta problemática, algumas confirmam a existência víeis racial no sistema de justiça criminal (Adorno, 1999) e outras não confirmam (Cano et al, 2010) .

Ramos e Musumeci (2005) fizeram uma pesquisa sobre abordagem policial e discriminação na cidade do Rio de Janeiro, onde concluíram que os resultados gerais da pesquisa não permitiram afirmar se existe de fato sobre-representação no total de pessoas abordadas pela PM, dos grupos que o senso comum aponta como alvos prediletos da suspeição policial. Uma vez que quando se considera a simples experiência de ter sido parado alguma vez e o número de abordagens sofridas, existia uma correlação consistente com o gênero e idade, nas não com raça, renda ou escolaridade, o peso dessas variáveis só aparecia quando se diferenciam tipos de abordagem e tipo de tratamento que a polícia dispensava aos cidadãos. 
Segundo os resultados desta pesquisa, os indícios de seletividade racial e social, só surgiam quando se examinava a incidência de revistas corporais, que eram um procedimento não muito comum em blitzes em veículos particulares (correspondendo a 19\% dos casos descritos), mas registrados em quase metade das abordagens no interior de ônibus ou trem, e praticamente obrigatório nas abordagens de pedestres 77\% dos casos (Ramos e Musumeci, 2005).

Outro estudo sobre a problemática do viés racial nos Estados do Rio de Janeiro e São Paulo $^{5}$, concluiu que a polícia empregava com mais frequência e com mais intensidade a sua força letal contra alguns grupos raciais (pretos e pardos), provando deste modo um viés racial no momento em que a polícia decidia usar suas armas de fogo. $\mathrm{O}$ que não se provou neste estudo foram às evidências sobre a possibilidade de um viés racial aplicado à decisão de usar ou não suas armas. E Tanto no Rio, como em São Paulo, os dados sugeriam "um suave escurecimento" aos olhos da polícia na percepção das vítimas, quando comparadas com o IML, conforme revelado pelo fato dos policiais tenderem a classificar mais vítimas como pretas. Não obstante, esse escurecimento era demasiadamente pequeno para explicar o desequilíbrio na distribuição racial das vítimas, o qual se atribuiu um viés racial nas ações policiais (Cano et al, 2005).

No judiciário, Adorno (1995) analisou uma amostra de casos de roubo qualificado na cidade de São Paulo no ano de 1990, onde concluiu a existência de viés racial na decisão judiciária, na qual a probabilidade de condenação era $9 \%$ superior para negros em comparação aos brancos. E tanto os pretos como os pardos tinham defensores privados e apresentavam testemunhas da defesa com menor frequência do que os brancos. Segundo a análise deste pesquisador e de outros anteriormente apresentados, a representação social, que relaciona "cor ou raça e criminalidade", contribuía para aumentar as probabilidades de condenação de pretos e pardos e diminuía as chances de condenação de brancos acusados por um mesmo tipo de delito.

Recentemente realizou-se no Brasil uma pesquisa ${ }^{6}$ com o objetivo de testar de forma confiável a existência de viés racial nas sentenças penais. No calculo da duração da pena em

\footnotetext{
${ }^{5}$ Cano, Ignacio et al (2005). Racial Bias in Police use of lethal force in Brasil (Viés Racial nas ações letais da polícia no Brasil. Esta pesquisa foi parte de um projeto realizado graças ao financiamento da Fundação Ford, para estudar o impacto da raça no sistema de segurança pública no Brasil. A equipe de pesquisadores, inclui Ignacio Cano, James Cavallaro, Ariel Alves, Cristina Jakimiak, Eduardo Ribeiro, Fernanda Souza, Rose Carvalho e Márcio Lázaro).

${ }^{6}$ Cano, Ignacio; Ribeiro, Ludmila; Meireles, Elisabet, (2010). Race, Crime and Criminal Justice in Brasil. In: Kalunta-Crumpton, Anita. Race, Crime and Criminal Justice: Internacional Perspectives. Palagrave macmillan. $2010 ; 207-241$.
} 
função dessas características e da cor do réu, achou-se que apenas em relação aos crimes de tráfico de drogas, as condenações contra os pretos pareciam ser significativamente superiores às dos brancos. Nos roubos, as sentenças contra os brancos eram algo mais elevado, mas não eram significativamente diferentes. Os pardos, por sua vez, não eram significativamente diferentes dos brancos em nenhum crime. (Cano el al, 2010)

Em suma, este estudo concluiu que as decisões tomadas pelos juízes estavam fortemente pautadas por uma estrutura normativa e sujeitas à revisão, de forma que o espaço para o surgimento de discriminação racial era reduzido. E se provavelmente existisse viés, ele era muito mais intenso e comum em outros estágios da relação entre o sistema de justiça criminal e o cidadão. (Idem)

\section{RELAÇÃO ENTRE ESTRANGEIRO, VIÉS RACIAL, DELIQUÊNCIA, E PRISÃO}

Para além dos questionamentos e discussões acima apresentados o propósito geral do presente estudo, se relaciona com uma problemática que reúne dois potenciais, que são a raça e a origem. Estes potenciais são importantes de serem analisados, porque provavelmente podem levar ao preconceito e discriminação na sociedade que estes estrangeiros vão ser inseridos, primeiro porque são de raça diferente da maioria dos nativos do país acolhedor, e o outro pelo fato de serem estrangeiros e se encontrarem presos nos sistema carcerário brasileiro.

Neste contexto, para a presente análise constatei a existência de pouca literatura no campo das ciências sociais que abordam o tema dos estrangeiros presos no Brasil. Optei por fazer uma análise usando teorias sociológicas e criminológicas, particularmente aquelas que procuram explicar a relação entre o estrangeiro, a delinquência e a prisão, assim como a questão do preconceito racial e institucional.

Perante as demais fontes de estudo e análise criminológicas na atualidade, adotei a proposta feita por Hassemer \& Conde [(2001) apud Gueiros Souza (2007)], que sugere a adoção de uma combinação de diferentes teorias em uma única, neste caso, combinar alguns fatos de teorias sociológicas e do etiquetamento, mas sem com isso produzir uma nova. Devendo a mesma ser capaz de reunir todos possíveis pontos de vista da criminalidade, encarando-a como problema individual e social; atendo-se tanto ao aspecto etiológico, quanto ao da reação social. Especificamente sobre a questão dos estrangeiros, as explicações mais atuais valem-se da ideia de que eles constituem, internacionalmente, num significativo grupo 
presente nas instâncias penais, seja como autores ou como vitimas de delitos. Portanto, a partir desta premissa, estes autores identificaram três principais fatos a combinar:

\section{- Discriminação institucional}

Neste fato, para a sua análise escolheu-se a perspectiva do Etiquetamento para se sustentar que as ações das agências formais de controle encontrar-se-iam impregnadas de prejulgamentos e estereótipos, particularmente aqueles difundidos pelos meios de comunicação, em desfavor do imigrante ou do estrangeiro temporário. Ou seja, o preconceito ou racismo estaria moldando a atuação dos órgãos policiais, as decisões judiciais e mesmo o trato penitenciário do infrator não nacional.

\section{- Diferenças étnico-culturais}

Este fato é argumentado, segundo os exemplos das pesquisas apontadas por García España [(2001) apud Gueiros Souza (2007)], que afirma que as diferenças étnico-culturais, mais do que fatores como racismo, a pobreza ou a marginalidade, constituem a principal motivação para a presença de estrangeiros nas estatísticas criminais. Tais pesquisas fazem referência à criminalidade das segunda e terceira gerações de imigrantes. Segundo García España, na literatura norte-americana é frequente, nos dias de hoje, compreender as minorias étnicas como coletivos marginalizados e fontes de conflito, minorias estas que se identificam com cidadãos mexicanos e afro-americanos. Por exemplo, a excessiva atenção dispensada nos Estados Unidos da América à delinquência dos negros como minoria étnica tem obscurecido uma realidade social latente, que é a dos novos imigrantes hispânicos em situação de ilegalidade naquele país.

\section{- $\quad$ Fatores socioeconômicos}

Conforme já expunha a criminologia crítica, aqueles que se encontram na base da escala social- dentre eles, grande maioria da população estrangeira- são sobre-estimados nas estatísticas de detenções e encarceramento. Dentro deste viés socioeconômico, Hans-Jörg Albrecht [(1997) apud Gueiros Souza (2007)] associa o elemento classe social aos fatores desemprego, educação deficitária e baixos rendimentos, experimentados tanto por imigrantes quanto por parte da população nacional como condicionantes das cifras de criminalidade não só na Alemanha, mas na generalidade da Europa. O problema, portanto, não seria exclusivo dos estrangeiros, mas de todos os que se encontrem em situação social similar. Este autor 
retorna a teoria da privação relativa, combinando-a com a teoria da subcultura delinquente, para explicar a presente questão. Em suma, ele enfoca o aspecto individual de que a pobreza do nativo ou do estrangeiro não conduz inexoravelmente ao delito, mas este pode ser perpetrado pela junção de frustrações pessoais (incapacidade de alcançar os bens e o estilo de vida alardeado pela sociedade de consumo), com a teoria macrossocial da debilidade dos controles sociais informais.

Em relação a outros princípios ou teorias que explicariam a possibilidade de existência de Viés Racial a serem usadas para o presente estudo, elas se basearam nos estudos anteriormente apresentados, sobre discriminação e viés racial no Brasil.

Neste âmbito, segundo estas pesquisas, o viés racial pode ocorrer em qualquer estágio do contato entre o cidadão e o sistema de justiça criminal, partindo da abordagem policial na rua até as condições de encarceramento, passando pelos inquéritos policiais, as denúncias do Ministério Público e as sentenças judiciais. Entretanto, o viés se faria mais presente nos encontros que estão menos pautados por normativas legais, que são menos registrados e estão menos sujeitos ao escrutínio de outros agentes públicos. Ela deveria ter menos espaço para se manifestar na tarefa de um juiz, cujos julgamentos estão submetidos a uma estrutura normativa bastante específica e são sempre suscetíveis a revisões da instância superior (Cano et al, 2005). E teria mais espaço para ocorrer na abordagem policial que está menos sujeita a qualquer tipo de supervisão ou controle posterior, sendo de suma importância, por se tratar da porta de entrada para o sistema de justiça criminal.

Em suma, de acordo com as pesquisas feitas sobre o viés racial, importa analisar o tratamento dado aos estrangeiros presos africanos, observando:

a) Benefícios judiciais e prisionais. Verificando se os membros das minorias raciais e de nacionalidade (estrangeiros africanos) podem ter suas liberdades condicionais recusadas, nos seus pedidos de Habeas Corpus.

b) As Sentenças. Se os Juízes podem indicar viés racial, consciente ou inconscientemente, incorrendo em uma probabilidade mais elevada de encontrar alguém culpado caso a pessoa seja de determinado grupo racial ou nacionalidade, ou pronunciando sentenças mais duras para membros desse grupo. Em outras palavras, pretende-se fazer esta análise com o intuito de observar se os estrangeiros africanos particularmente são tratados de forma diferente dos brancos em um mesmo crime e com as mesmas circunstâncias. 


\section{PERFIL DOS PRESOS ESTRANGEIROS NO SISTEMA PENITENCIÁRIO DO ESTADO DO RIO DE JANEIRO}

Para a análise do perfil dos presos estrangeiros, adotou-se um método similar ao utilizado por Combessie (2001), para tratar do perfil de presos na França. Este método consiste em fazer um levantamento das características sociológicas dos presos tendo em mente diferentes medidas quantitativas, tais como o cruzamento em termos de valores absolutos e relativos das variáveis a serem utilizadas para traçar este perfil. Partindo daí, me interessou observar a distribuição, para estrangeiros (africanos e não-africanos) e brasileiros, de variáveis sociodemográficas.

Combessie (2001) observou ainda os fluxos de entrada e saída dos presídios e comparou a distribuição das variáveis do perfil para população carcerária e não carcerária. Infelizmente os dados que possuímos, seja no Censo Demográfico do $\mathrm{IBGE}^{7}$, seja nas bases de dados e sistemas de informação penitenciários, como o Sistema Integrado de Informações Penitenciárias $\left(\right.$ INFOPEN) ${ }^{8}$, o Censo Penitenciário e os sistemas estaduais, não estão disponíveis ou possuem má qualidade.

Neste contexto, utilizaram-se as seguintes variáveis consideradas importantes para traçar um perfil do presidiário: a nacionalidade dos presos, que para o presente estudo é a variável mais importante, sendo subdividida em três categorias, a citar, Brasileiro, Africano e Estrangeiro não Africano; a cor do preso, variável de interesse por possibilitar a observação de um possível viés racial; sexo; idade; nível escolar; estado civil e; os tipos crimes pelos quais os presidiários foram condenados.

Para melhor análise do perfil do preso tendo em consideração a presença ou ausência de diferenciais segundo a nacionalidade e suas características raciais, além das variáveis expostas acima poderiam ser consideradas como pertinentes para o estudo do perfil, variáveis como o status social ou socioeconômico dos presos, como ressalta Adorno (1995) e Combessie (2001), que descrevem a posição social ocupada pelo indivíduo no momento de seu ingresso no sistema prisional; a própria profissão que os presidiários exerciam antes da

\footnotetext{
${ }^{7}$ IBGE: www.ibge.gov.br.

${ }^{8}$ Sistema de Informações Penitenciárias do Departamento Penitenciário Nacional do Ministério da Justiça INFOPEN: www.portal.mj.gov.br/data.
} 
condenação; e variáveis que expressassem laços e estruturas familiares. Para o presente estudo, entretanto, não existiam disponíveis muitas variáveis nesse sentido ${ }^{9}$.

\subsection{Variações do Perfil dos Presos no Estado do Rio de Janeiro segundo Nacionalidade}

Considerando o tema deste trabalho, o perfil que será traçado nesta seção tem como foco os diferenciais, em termos das variáveis e características sociais apontadas anteriormente, segundo a nacionalidade dos presos. Acredito que ao visualizar tais variações poderei refletir melhor sobre as dinâmicas e contextos que produzem estas possíveis diferenças.

O número de estrangeiros no Sistema Penitenciário é relativamente pequeno, comparado ao percentual de presos brasileiros. No Brasil, segundo os dados do INFOPEN para 2010, existiam apenas 3.397, menos de $1 \%$ dos mais de 400.000 apenados. No Rio de Janeiro, no mesmo ano, esse número era de 175 pessoas, enquanto em São Paulo, que possui a maior população penitenciária do país, esse número chegava a 2.047 presos, também em 2010. Neste contexto, os presos africanos no Sistema Penitenciário são poucos - no Brasil, aproximadamente $25 \%$ dos estrangeiros presos; e $0,2 \%$ do número total de pessoas aprisionadas.

Na base de dados do SIPEN, que considera dez anos (1997 a 2006), uma proporção de estrangeiros similar à do Brasil e do Estado do Rio de Janeiro no ano de 2010, foi encontrada. Constam na base 551 presos estrangeiros (como mostra a Tabela 1 no Anexo 1), que correspondem a $0,8 \%$ dos presos. Os africanos são $0,2 \%$ dos presos, e $27,4 \%$ dos estrangeiros.

Em relação ao continente ou região de origem dos presos, Gueiros Souza (2007), em seu estudo sobre o perfil dos presos estrangeiros no Brasil, mostrou que mais da metade dos presos estrangeiros no Brasil, no ano de 2004, provinha de países da própria América do Sul (54,8\%), seguindo-se de Europa e África, com percentuais muito próximos - 18,4\% e 17,1\%, respectivamente. Tais resultados, foram contrapostos às conclusões apontadas por outro

\footnotetext{
${ }^{9}$ Existe na base de dados uma variável que expressava a profissão do apenado, mas esta apresenta problemas diversos, desde o seu preenchimento até a impossibilidade de uma codificação em tempo viável para a realização das análises. Optamos então por descartar pelo menos temporariamente esta variável, embora ela seja importante e possa inclusive ser recuperada no texto final da dissertação.
} 
estudo, do ILANUD $(1997)^{10}$, sobre as mudanças do perfil penitenciário do Estado de São Paulo dos anos 50 aos 90, segundo o qual, a maioria dos presos estrangeiros provinha do continente africano, superando mesmo o número de presos que vinham da América Latina.

Os dados do INFOPEN, para o ano de 2010, mostram que para o Brasil, os africanos não são proporcionalmente a maioria, já que 49,5\% dos estrangeiros presos são latinos americanos, enquanto que os africanos são aproximadamente $25 \%$. No Rio de Janeiro, o percentual de africanos entre os presos estrangeiros está muito próximo dos números nacionais, ficando em aproximadamente $27 \%$. Uma especificidade do que ocorre neste estado é que a maioria dos estrangeiros é formada por europeus, que constituem $43 \%$ dos estrangeiros. No Estado de São Paulo, a proporção de africanos é maior, um resultado que vai à direção dos percentuais apontados pelo ILANUD (1997). Os africanos correspondem a 36\% dos estrangeiros presos, o mesmo percentual dos latino-americanos. O Gráfico 1 (Anexo 2) resume estes dados.

Entre os estrangeiros que constam no banco de dados do SIPEN, a distribuição para o Estado do Rio de Janeiro foi um pouco diferente daquela proveniente do INFOPEN, de 2010, como pode ser observado na Tabela 2 (Anexo 3). O percentual dos africanos de $28 \%$ é bem próximo dos $27 \%$ encontrados em 2010, e mostra certa estabilidade em sua participação.

No que se refere ao nosso objeto de estudo, que enfatiza os presos estrangeiros africanos, constata-se que dos 54 países que constituem o continente, 18 estão representados (Ver a Tabela 3, Anexo 4). Verifica-se que os angolanos são maioria entre os presos africanos, seguidos pelos sul-africanos com a mesma proporção percentual.

Com estes resultados, verifica-se que este pequeno número de presos estrangeiros, sobretudo africanos, limita as possibilidades de cruzamentos de variáveis. Deste modo, nas análises que se seguem serão apresentadas apenas tabelas que cruzam as diferentes variáveis sociais com as três principais categorias de nacionalidade (brasileiros, estrangeiros nãoafricanos e africanos). Quaisquer tabulações que cruzassem mais de duas variáveis teriam células com pouquíssimos casos o que dificultaria a interpretação dos percentuais.

\subsubsection{Comparação do Perfil dos Presos segundo a Nacionalidade: Sexo}

\footnotetext{
${ }^{10}$ ILANUD. Sistema Penitenciário: mudanças de Perfil dos anos 50 aos 90. Revista do ILANUD, nº 6, 1997. (ILANUD - Instituto Latino - Americano das Nações Unidas para Prevenção do Delito e Tratamento do Delinquente).
} 
Analisando a distribuição por sexo dos apenados conjuntamente com a nacionalidade, constata-se que, proporcionalmente, os estrangeiros possuem um perfil mais feminino, sobretudo, para os africanos. Enquanto o percentual de apenados brasileiros do sexo feminino é pouco menor do que $6 \%$, o percentual de estrangeiras não-africanas chega a $17 \%$ e entre os africanos, aproximadamente $23 \%$ são mulheres. Essa relação é estatisticamente significativa $^{11}$, de modo que é possível afirmar que existe associação significativa entre nacionalidade e o perfil por sexo dos apenados. (Ver na Tabela 4 do Anexo 5)

\subsubsection{Comparação do Perfil dos Presos segundo a Nacionalidade: Idade}

Antes de começarmos a falar sobre as diferenças que existem nos perfis etários de brasileiros e estrangeiros, cabe ressaltar que o presente estudo, por definição, possui um limite de idade inferior, que exclui indivíduos com menos de 18 anos de idade. Vale ainda comentar que a idade foi calculada com base na data do delito, sendo, portanto, a idade do apenado quando este cometeu o crime.

No que tange ao perfil etário, os estrangeiros apenados possuem médias mais elevadas de idade, em relação aos presos brasileiros. Essa diferença é mais acentuada em relação aos presos não-africanos, chegando a cerca de 10 anos em média, mas também é bem grande em relação aos presos africanos (Ver na Tabela 5 do Anexo 6). A associação entre as variáveis foi também estatisticamente significativa, segundo o teste de análise de variância $(\mathrm{ANOVA})^{12}$.

\subsubsection{Comparação do Perfil segundo a Nacionalidade: Grau de Instrução}

Com vista a analisar de forma mais clara a variável grau de instrução, uma vez que a mesma apresentava várias categorias referentes a diferentes séries e níveis de escolaridade, optamos por uma agregação que reduziu o número de categorias para as seguintes: a) Sem formação ou Ensino Fundamental; b) Ensino Médio; c) Ensino Superior. Essa variável apresentava um elevado percentual de casos sem informação ( $28 \%$ dos casos), de modo que um número menor de categorias possibilitou o maior número de casos nos cruzamentos.

Como mostra a Tabela 6 (Anexo 7), os estrangeiros de modo geral e os africanos em particular, possuem um perfil mais elevado de instrução que os apenados brasileiros.

\footnotetext{
${ }^{11}$ Com $\alpha=0,05$; Estatística $\mathrm{X}^{2}=164,28$; g.l. = 2; p-valor < 0,00.

${ }^{12} \operatorname{Com} \alpha=0,05$; Estatística $\mathrm{F}=307$; g.l. $=2$; p-valor $<0,00$.
} 
Enquanto a grande massa de presos brasileiros não possui formação ou possui apenas o Ensino Fundamental, mais da metade dos presos estrangeiros possuem Ensino Médio ou Ensino Superior. Nota-se ainda um percentual comparativamente maior, entre os presos africanos, de indivíduos com nível superior. O teste de significância demonstrou uma associação entre nacionalidade e nível de instrução ${ }^{13}$.

\subsubsection{Comparação do Perfil dos Presos segundo a Nacionalidade: Estado Civil}

Quanto ao estado civil, inicialmente se verificou que a categoria mais relevante para a análise da relação com a nacionalidade era a condição de solteiro. Deste modo, utilizamos apenas duas categorias: Solteiro e Não-Solteiro, que inclui casados, viúvos e vários tipos de separações conjugais. A Tabela 7 (Anexo 8) mostra uma ampla diferença entre os perfis maritais de brasileiros e estrangeiros, os primeiros são significativamente mais solteiros ${ }^{14}$.

\subsubsection{Comparação do Perfil dos Presos segundo a Nacionalidade: Cor}

Antes de fazer a análise do perfil segundo a cor, importa citar que vários estudos no Brasil sobre discriminação racial, consideram a variável cor, como sendo de difícil interpretação e que esta vem sofrendo alterações quanto a sua definição no decorrer dos anos. O Instituto Brasileiro de Geografia e Estatística (IBGE) em 1980 trabalhou sobre quatro categorias (branco, preto, amarelo e pardo), e em 1991 introduziu a categoria indígena; já no Censo Demográfico de 2000, a variável foi categorizada na seguinte ordem: branca, preta, amarela, parda e indígena.

Analisando a variável cor na base de dados do SIPEN, encontramos inicialmente dois problemas. O primeiro se refere ao percentual de casos sem a informação da cor, estes representam 22,6\% dos casos. Constatamos, em segundo lugar, dificuldades em termos das categorias utilizadas pelo sistema, que incluem ambivalências como a existência de uma categoria denominada mulato. As categorias cor amarela e mulata, com pouquíssima informação, foram agregadas às categorias: branca e parda, respectivamente. Neste contexto, para a variável foram selecionadas as categorias: branca, parda e preta.

O perfil racial dos apenados constitui uma dimensão fundamental para análise na medida em que ele serve para diferenciar radicalmente os perfis de estrangeiros africanos e não-africanos. Conforme a Tabela 8 (Anexo 9), os estrangeiros não-africanos são predominantemente brancos, de modo que enquanto $85 \%$ dos presos estrangeiros são

${ }^{13}$ Com $\alpha=0,05$; Estatística $X^{2}=1447,14$; g.l. = 4; p-valor < 0,00.

${ }^{14}$ Com $\alpha=0,05$; Estatística $\mathrm{X}^{2}=300,22 ;$ g.l. $=2$; p-valor $<0,00$. 
brancos, apenas $7 \%$ dos presos africanos o são. Por outro lado, $83 \%$ dos presos africanos estão classificados na categoria pretos, contra apenas $2 \%$ dos não-africanos. Os brasileiros apresentam um perfil mais distribuído em termos das categorias de cor, apresentando uma maior participação da categoria pardos em seu perfil (38\% contra $12 \%$ dos não-africanos e 9,5\% dos africanos), embora o percentual de brancos (36\% dos presos brasileiros) e de pretos também seja relativamente elevado. As relações apresentadas foram estatisticamente significativas ${ }^{15}$.

\subsubsection{Comparação entre o Tipo de Crime e a Nacionalidade dos presos}

Com vista a analisar a possível existência de discriminação institucional e viés racial no Sistema de Justiça Criminal, a partir dos dados acima expostos, importa relacionar os mesmos com os tipos de crimes pelos quais os apenados foram condenados. Para a análise por tipo de crime, codificamos os delitos que se revelaram mais frequentes no banco de processos penais com base na categorização utilizada por Julião (2009). Desta forma, foram codificados os artigos dos crimes segundo sua definição no Código Penal, como resultado, as seguintes categorias foram utilizadas: tráfico, homicídio, roubo, furto, estelionato/fraudes e lesão corporal.

Quando analisamos os perfis criminais segundo nacionalidade dos apenados constatamos que a diferença mais significativa se dá no perfil dos presos africanos, na medida em que $85 \%$ dos presos africanos cumprem pena por tráfico de drogas (ver na Tabela 9 do Anexo 10). Entre os estrangeiros não-africanos o percentual de condenados por tráfico pode também ser destacado como elevado, ficando em $64 \%$, enquanto o mesmo percentual entre os presos brasileiros ficou em pouco menos do que 30\%. Entre os estrangeiros não-africanos pode-se também destacar um percentual considerável de presos por furto $(26,5 \%$ contra $13 \%$ dentre os brasileiros e apenas $4 \%$ dos africanos). Por sua vez, entre apenados brasileiros o crime mais frequente de condenação foi o roubo (com 49,7\%), um crime praticamente sem expressão para os estrangeiros em termos percentuais. As relações encontradas foram estatisticamente significativas ${ }^{16}$.

Dado que o perfil criminal dos apenados africanos é predominantemente composto por condenados por crimes relacionados ao tráfico de drogas, surge a necessidade de observar com maior detalhe essa questão, qualificando o tipo de tráfico no qual se baseou a condenação. Assim, tendo em vista o objeto analisado neste trabalho, uma hipótese a ser

\footnotetext{
${ }^{15} \mathrm{Com} \alpha=0,05 ;$ Estatística $\mathrm{X}^{2}=280,07$; g.l. $=4$; p-valor $<0,00$

${ }^{16}$ Com $\alpha=0,05$; Estatística $X^{2}=539,41 ;$ g.l. = 10; p-valor < 0,00.
} 
considerada é que os apenados estrangeiros, em específico os africanos, apresentam um percentual de participação no crime de tráfico internacional superior ao dos brasileiros, mesmo entre aqueles condenados por tráfico.

Para fazer a Tabela 10 e a Tabela 11 foi criada uma nova variável a partir da capitulação do processo. Esta recupera justamente a informação do crime de tráfico internacional de drogas (art.18, I da lei 6368/76). A partir daí, o cruzamento entre essa nova variável e a nacionalidade do apenado permitiu observar o perfil criminal dos apenados (Tabela 10 do Anexo 11) e dos condenados por tráfico (Tabela 11 do Anexo 12). Para fazer esta última tabela, foram selecionados apenas os casos cujo tipo do crime foi anteriormente classificado como tráfico de drogas.

As tabelas anteriores nos mostram que o perfil dos estrangeiros presos, além de caracterizado pelas condenações por tráfico de drogas, é também fortemente relacionado ao tráfico internacional. Entre os apenados africanos $70 \%$ tiveram esse agravante penal em suas condenações, e o número sobe para $92 \%$ se consideramos apenas os traficantes de drogas. Entre os estrangeiros estes percentuais de envolvimento com o tráfico internacional também são bem acentuados, chegando $43 \%$ entre os apenados, mas, principalmente, a $84 \%$ entre os traficantes. Para o perfil dos brasileiros, contudo, esse não constitui um crime importante e mesmo considerando apenas os traficantes, os percentuais não passam de $2 \%$.

\section{CONSIDERAÇÕES FINAIS}

Em suma, a análise sobre a possibilidade de existência de viés racial no sistema de justiça criminal ainda não foi concluído, pois faz parte de um estudo ainda em andamento no decurso do meu mestrado. Neste contexto, o que nos resta concluir em momento é a análise do perfil dos presos estrangeiros no estado do Rio de Janeiro.

Os apenados estrangeiros possuem um perfil mais feminino e com maior idade média em relação aos apenados brasileiros (Tabela 12 do Anexo 13). Possuem também um maior nível educacional e são menos solteiros. O grande diferencial entre os estrangeiros está na variável cor, já que os estrangeiros africanos são predominantemente pretos e os estrangeiros não-africanos são predominantemente brancos. Os apenados brasileiros, por sua vez, comparados aos presos estrangeiros, são mais homens, mais jovens, solteiros e possuem instrução mais baixa. Em relação à cor, são comparativamente mais pardos, embora o 
percentual de brancos, pardos e pretos esteja bem distribuído, o que não ocorre com os estrangeiros.

Em relação aos crimes e condenação, ficou claro o maior envolvimento proporcional dos estrangeiros com os crimes relacionados ao tráfico de drogas, o que foi mais evidente para os apenados africanos. Nesse contexto, é importante destacar o peso maior da participação dos estrangeiros e principalmente dos africanos, nos crimes de tráfico internacional de drogas.

\section{Referências Bibliográficas:}

Adorno, Sérgio . "Discriminação Racial e Justiça Criminal em São Paulo". Novos Estudos. CEBRAP, 1995.

Albrecht, Hans-Jörg . Ethnic minorities, crime, and Criminal Justice in Germany. Ethinicity, crime, and immigration: Comparative and cross-national perspectives. Tonry, Michal (Org.). Chicago: The University of Chicago Press, 1997.

Assis, Gláucia de Oliveira . Texto Nepo 41: Estar Aqui, Estar Lá ... Uma cartografia da vida entre o Brasil e os Estados Unidos. Campinas: Núcleo de Estudos de População/UNICAMP, 2002.

Becker, Howard. Outsider.Criminological perspectives: A reader. Muncie, John, Maclauglhin, Eugene \& Langan, Mary (Org.). London: Sage, 1996.

Cano, Ignacio; Ribeiro, Ludmila; Meireles, Elisabet. Race, Crime and Criminal Justice in Brasil. In: Kalunta-Crumpton, Anita. Race, Crime and Criminal Justice: Internacional Perspectives. Palagrave macmillan. 207-241; 2010.

Combessie, Philipe. Sociologie de la Prison. Paris: Éditions La Decouverte. Colectio Repères, 2001.

Costa-Ribeiro, Carlos Antônio . Cor e Criminalidade. Estudo e Análise da Justiça no Rio de Janeiro (1900-1930). Rio de Janeiro. Editora UFRJ, 1995. 
Dicionário de Ciências Sociais. Rio de Janeiro: Fundação Getúlio Vargas,1986.

Fernandes, Florestan . A Integração do Negro na Sociedade de Classes. São Paulo: Dominus Editora, 1965.

García España, Elisa. Inmigracion y delincuencia em España: Análise criminológicas.Valencia: Tirant lo Blanch, 2001.

García-Pablo de Molina, António. Tratado de Criminologia. $3^{\mathrm{a}}$ ed. Valencia: Tirant lo Blanch, 2003.

Gould, W.T.S. Population movements and the changing world order: An introduction. In Population movements and the changing world order. John Wiley and Sons. New York, 1994.

Gueiros Souza, Arthur de Brito. Presos Estrangeiros no Brasil: Aspectos Jurídicos Criminológicos. Editora Lumen Juris. Rio de Janeiro, 2007.

Hasenbalg, Carlos . Discriminação e desigualdades raciais no Brasil. Rio de Janeiro. Graal, 1979.

Hessemer, Winfried \& Muñoz Conde, Francisco. Introducción a la Criminología. Valencia: Tirant lo Blanch, 2001.

Ramos, Silvia e Musumeci, Leonarda. Elemento Suspeito: abordagem policial e discriminação na cidade do Rio de Janeiro; com artigos de paul Amar e Marcelo Paixão. Rio de Janeiro: Civilização Brasileira, 2005.

Ribeiro, Ludmila. "Impunidade no Sistema de Justiça Criminal Brasileiro: Uma Revisão dos Estudos Produzidos sobre o Tema". Research Paper Series, 48, LatinAmerican and Iberian Institute (LAII). New Mexico, University of New México, 2009.

Silva, Jorge da. Direitos Civis e Relações Raciais no Brasil. Rio de Janeiro. $1^{\text {a }}$ ed. LUAM, 1994.

Shecaria, Sérgio Salomão. Criminologia. São Paulo: Revista dos Tribunais, 2004.

Southerland, Edwin H., Cressey, Donald R. \& Luckwnbill, David F. Principles of Criminology. $11^{\text {th }}$ ed. New York: General Hall, 1992. 
Rocha, João Luís Moraes. Reclusos estrangeiros: Um estudo exploratório. Coimbra: Almeida, 2001.

\section{Pesquisas e Teses}

- Cano, Ignacio et al (2005). Racial Bias in Police use of lethal force in Brasil (Viés Racial nas ações letais da polícia no Brasil. Esta pesquisa foi parte de um projeto realizado graças ao financiamento da Fundação Ford, para estudar o impacto da raça no sistema de segurança pública no Brasil. A equipe de pesquisadores, inclui Ignacio Cano, James Cavallaro, Ariel Alves, Cristina Jakimiak, Eduardo Ribeiro, Fernanda Souza, Rose Carvalho e Márcio Lázaro).

- Julião, Elionardo Fernandes. Tese de Dissertação de Doutorado: A Ressocialização através do Estudo e do Trabalho no Sistema Penitenciário Brasileiro. Universidade do Estado do Rio de Janeiro, 2009.

\section{Legislação}

Constituição Federal de 1988;

Código Penal Brasileiro, Decreto Lei n. ${ }^{\circ} 2.848$ de 7 de Dezembro de 1940;

Lei n. $^{\circ}$ 7.210, de 11 de Julho de 1984. Lei de Execução Penal.

Lei n. ${ }^{\circ}$ 6.815, de 19 De Agosto de 1980. Define a situação jurídica do estrangeiro no Brasil, cria o Conselho Nacional de Imigração. 


\section{Anexo 1}

Tabela 1. Número de apenados segundo Nacionalidade

\begin{tabular}{lrc}
\hline \multicolumn{1}{c}{ Nacionalidade } & \multicolumn{1}{c}{ FREQ } & \multicolumn{1}{c}{$\%$} \\
\hline Brasileiro & 66156 & 99,2 \\
\hline Estrangeiro não-africano & 397 & 0,6 \\
\hline Africano & 154 & 0,2 \\
\hline Total & 66707 & 100,0 \\
\hline Fonte: SIPEN/VEP/RJ (1997 a 2006).
\end{tabular}

Anexo 2

GRÁFICO 1: Apenados Estrangeiros por Continente de Origem (\%)

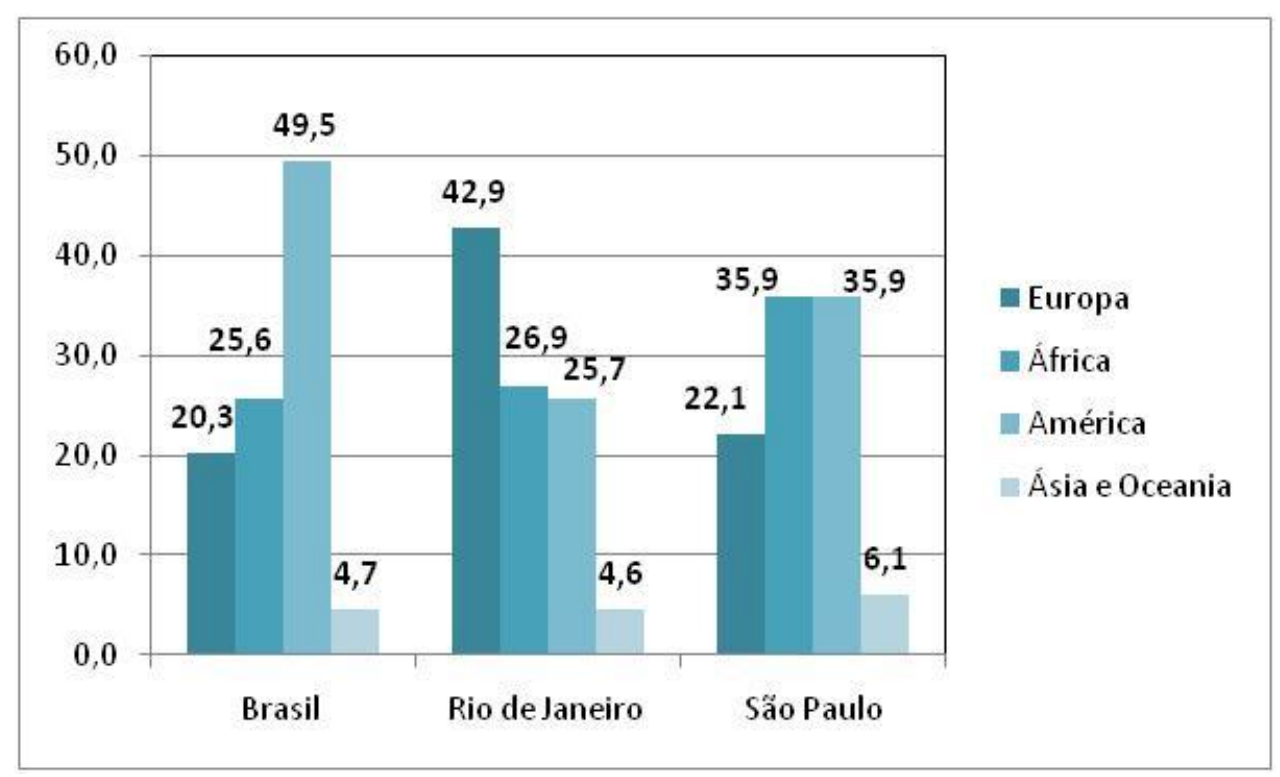

Fonte: INFOPEN (2010).

Anexo 3

Tabela 2. Apenados segundo continente de origem

\begin{tabular}{lrcc}
\hline \multicolumn{1}{c}{ Continente de Origem } & FREQ & \% & \% válido \\
\hline Europa & 197 & 35,8 & 35,9 \\
\hline África & 154 & 27,9 & 28,1 \\
\hline América & 180 & 32,7 & 32,8 \\
\hline Ásia e Oceania & 17 & 3,1 & 3,1 \\
\hline Casos Válidos & 548 & 99,5 & 100,0 \\
\hline Estrangeiro não identificado & 3 & 0,5 & \\
\hline Total de Estrangeiros & 551 & 100,0 & \\
\hline
\end{tabular}

Fonte: SIPEN/VEP/RJ (1997 a 2006). 
Anexo 4

Tabela 3. Apenados em Países Africanos

\begin{tabular}{lrc}
\hline \multicolumn{1}{c}{ País } & FREQ & $\%$ \\
\hline AFRICA DO SUL & 36 & 23,4 \\
\hline ANGOLA & 62 & 40,3 \\
\hline CAMARÕES & 2 & 1,3 \\
\hline CONGO & 1 & 0,6 \\
\hline CABO VERDE & 3 & 1,9 \\
\hline EGITO & 1 & 0,6 \\
\hline GANA & 6 & 3,9 \\
\hline GUINÉ BISSAU & 10 & 6,5 \\
\hline GUINÉ CONACRY & 1 & 0,6 \\
\hline LIBÉRIA & 1 & 0,6 \\
\hline MARROCOS & 1 & 0,6 \\
\hline NAMIBIA & 5 & 3,2 \\
\hline NIGERIA & 14 & 9,1 \\
\hline QUENIA & 2 & 1,3 \\
\hline RUANDA & 1 & 0,6 \\
\hline SERRA LEOA & 2 & 1,3 \\
\hline TANZÂNIA & 4 & 2,6 \\
\hline ZAIRE & 2 & 1,3 \\
\hline Total de Países Africanos & 154 & 100,0 \\
\hline
\end{tabular}

Fonte: SIPEN/VEP/RJ (1997 a 2006).

\section{Anexo 5}

Tabela 4. Apenados segundo Sexo e Nacionalidade ${ }^{17}$

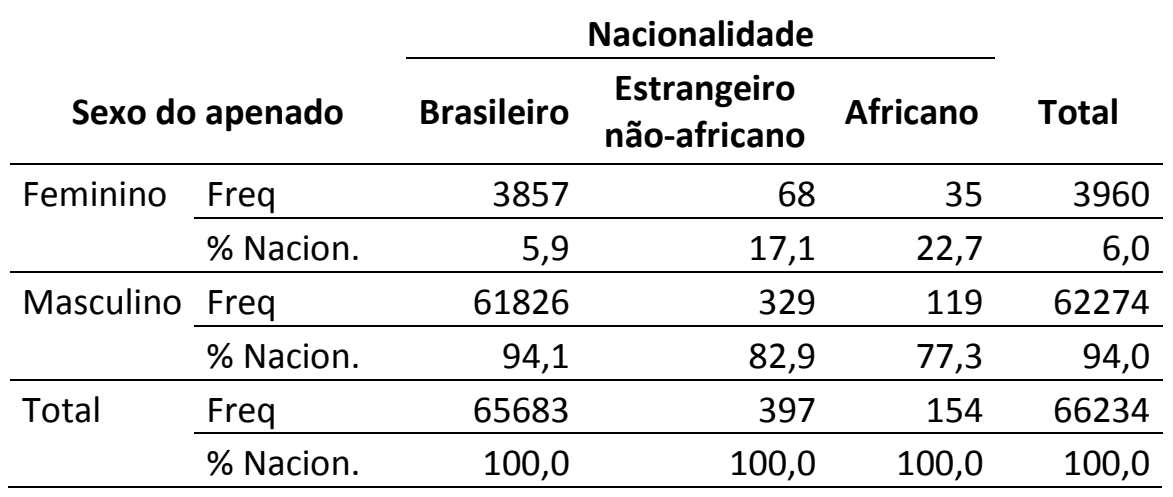

Fonte: SIPEN/VEP/RJ (1997 a 2006).

${ }^{17}$ Com $\alpha=0,05 ;$ Estatística $X^{2}=164,28 ;$ g.l. = 2; p-valor < 0,00. 


\section{Anexo 6}

Tabela 5. Apenados segundo Idade e Nacionalidade ${ }^{18}$

\begin{tabular}{lccc}
\hline \multicolumn{1}{c}{ Nacionalidade } & Média & No casos & $\begin{array}{c}\text { Desvio } \\
\text { Padrão }\end{array}$ \\
\hline Brasileiro & 26,4 & 64813 & 8,5 \\
\hline Estrangeiro não-africano & 36,6 & 388 & 11,8 \\
\hline Africano & 31,9 & 151 & 8,0 \\
\hline Total & 26,5 & 65352 & 8,5 \\
\hline
\end{tabular}

Fonte: SIPEN/VEP/RJ (1997 a 2006).

\section{Anexo 7}

Tabela 6. Apenados segundo Grau de Instrução e Nacionalidade ${ }^{19}$

\begin{tabular}{llrrrr} 
& & \multicolumn{3}{c}{ Nacionalidade } & \\
\cline { 2 - 5 } $\begin{array}{c}\text { Grau de Instrução } \\
\text { do apenado }\end{array}$ & & Brasileiro & $\begin{array}{c}\text { Estrangeiro } \\
\text { não-africano }\end{array}$ & Africano & Total \\
\hline Sem Formação ou & Freq & 43898 & 132 & 52 & 44082 \\
\cline { 2 - 5 } Fundamental & $\%$ Nacion. & 93,2 & 47,8 & 44,1 & 92,8 \\
\hline Ensino Médio & Freq & 2698 & 105 & 45 & 2848 \\
\cline { 2 - 5 } & $\%$ Nacion. & 5,7 & 38,0 & 38,1 & 6,0 \\
\hline Ensino Superior & Freq & 500,0 & 39,0 & 21,0 & 560 \\
\cline { 2 - 5 } & $\%$ Nacion. & 1,1 & 14,1 & 17,8 & 1,2 \\
\hline Total & Freq & 47096 & 276 & 118 & 47490 \\
\cline { 2 - 5 } & $\%$ Nacion. & 100,0 & 100,0 & 100,0 & 100,0 \\
\hline
\end{tabular}

Fonte: SIPEN/VEP/RJ (1997 a 2006).

\section{Anexo 8}

Tabela 7. Apenados segundo Estado Civil e Nacionalidade ${ }^{20}$

\begin{tabular}{llrrrr} 
& & \multicolumn{3}{c}{ Nacionalidade } & \\
\cline { 3 - 5 } Estado Civil & & Brasileiro & $\begin{array}{c}\text { Estrangeiro } \\
\text { não-africano }\end{array}$ & Africano & Total \\
\hline Solteiro & Freq & 55078 & 223 & 93 & 55394 \\
\cline { 2 - 5 } & \% Nacion. & 87,6 & 60,9 & 65,0 & 87,4 \\
\hline Não Solteiro & Freq & 7793 & 143 & 50 & 7986 \\
\cline { 2 - 5 } & & & &
\end{tabular}

$\overline{{ }^{18} \mathrm{Com} \alpha=0,05 ; \text { Estatística } \mathrm{F}=307}$; g.l. = 2; p-valor < 0,00.

${ }^{19}$ Com $\alpha=0,05$; Estatística $\mathrm{X}^{2}=1447,14$; g.l. $=4$; $\mathrm{p}$-valor $<0,00$.

${ }^{20}$ Com $\alpha=0,05$; Estatística $X^{2}=300,22 ;$ g.l. $=2$; p-valor $<0,00$. 


\begin{tabular}{llrrrr} 
& \% Nacion. & 12,4 & 39,1 & 35,0 & 12,6 \\
\hline \multirow{2}{*}{ Total } & Freq & 62871 & 366 & 143 & 63380 \\
\cline { 2 - 6 } & \% Nacion. & 100,0 & 100,0 & 100,0 & 100,0 \\
\hline
\end{tabular}

Fonte: SIPEN/VEP/RJ (1997 a 2006).

\section{Anexo 9}

Tabela 8. Cor dos Apenados em Relação à Nacionalidade ${ }^{21}$

\begin{tabular}{llrrrr}
\multirow{2}{*}{$\begin{array}{c}\text { Cor do } \\
\text { Apenado }\end{array}$} & Brasileiro & $\begin{array}{c}\text { Estrangeiro } \\
\text { não-africano }\end{array}$ & Africano & \multirow{2}{*}{ Total } \\
\cline { 2 - 5 } Branca & Freq & 18706 & 169 & 3 & 18878 \\
\cline { 2 - 5 } & $\%$ Nacion. & 36,4 & 85,4 & 7,1 & 36,6 \\
\hline Parda & Freq & 19598 & 25 & 4 & 19627 \\
\cline { 2 - 5 } & $\%$ Nacion. & 38,1 & 12,6 & 9,5 & 38,0 \\
\hline Preta & Freq & 13095,0 & 4,0 & 35 & 13134 \\
\cline { 2 - 5 } & $\%$ Nacion. & 25,5 & 2,0 & 83,3 & 25,4 \\
\hline Total & Freq & 51399 & 198 & 42 & 51639 \\
\cline { 2 - 5 } & $\%$ Nacion. & 100,0 & 100,0 & 100,0 & 100,0 \\
\hline
\end{tabular}

Fonte: SIPEN/VEP/RJ (1997 a 2006).

\section{Anexo 10}

Tabela 9. Tipo de Crime segundo Nacionalidade ${ }^{22}$

\begin{tabular}{|c|c|c|c|c|c|}
\hline \multirow[b]{2}{*}{ Tipo de Crime } & & \multicolumn{3}{|c|}{ Nacionalidade } & \multirow[b]{2}{*}{ Total } \\
\hline & & Brasileiro & $\begin{array}{l}\text { Estrangeiro } \\
\text { não-africano }\end{array}$ & Africano & \\
\hline \multirow[t]{2}{*}{ Tráfico } & Freq & 14737 & 204 & 117 & 15058 \\
\hline & $\%$ Nacion. & 29,7 & 64,4 & 85,4 & 30,0 \\
\hline \multirow[t]{2}{*}{ Homicídio } & Freq & 1976 & 6 & 0 & 1982 \\
\hline & $\%$ Nacion. & 4,0 & 1,9 & 0,0 & 4,0 \\
\hline \multirow[t]{2}{*}{ Roubo } & Freq & 24691 & 10 & 4 & 24705 \\
\hline & $\%$ Nacion. & 49,7 & 3,2 & 2,9 & 49,3 \\
\hline \multirow[t]{2}{*}{ Furto } & Freq & 6502 & 84 & 6 & 6592 \\
\hline & $\%$ Nacion. & 13,1 & 26,5 & 4,4 & 13,1 \\
\hline \multirow[t]{2}{*}{ Estelionato/fraudes } & Freq & 706 & 7 & 7 & 720 \\
\hline & $\%$ Nacion. & 1,4 & 2,2 & 5,1 & 1,4 \\
\hline \multirow[t]{2}{*}{ Lesão corporal } & Freq & 1088 & 6 & 3 & 1097 \\
\hline & $\%$ Nacion. & 2,2 & 1,9 & 2,2 & 2,2 \\
\hline \multirow[t]{2}{*}{ Total } & Freq & 49700 & 317 & 137 & 50154 \\
\hline & \% Nacion. & 100,0 & 100,0 & 100,0 & 100,0 \\
\hline
\end{tabular}

${ }^{21}$ Com $\alpha=0,05$; Estatística $X^{2}=280,07$; g.l. = 4; p-valor < 0,00.

${ }^{22}$ Com $\alpha=0,05$; Estatística $X^{2}=539,41$; g.l. = 10; $p$-valor $<0,00$. 
Fonte: SIPEN/VEP/RJ (1997 a 2006).

\section{Anexo 11}

Tabela 10. Tráfico Internacional segundo Nacionalidade do Apenado

\begin{tabular}{llrrrr} 
& & \multicolumn{3}{c}{ Nacionalidade } & \\
\cline { 2 - 5 } Tráfico Internacional & & Brasileiro & $\begin{array}{c}\text { Estrangeiro } \\
\text { não-africano }\end{array}$ & Africano & Total \\
& & 65991 & 224 & 46 & 66261 \\
\hline Outros crimes & Freq & 99,8 & 56,4 & 29,9 & 99,3 \\
\cline { 2 - 6 } & $\%$ Nacion. & 165 & 173 & 108 & 446 \\
\hline Tráfico Internacional & Freq & 0,2 & 43,6 & 70,1 & 0,7 \\
\cline { 2 - 6 } & $\%$ Nacion. & 66156 & 397 & 154 & 66707 \\
\hline Total & Freq & 100,0 & 100,0 & 100,0 & 100,0 \\
\hline
\end{tabular}

Fonte: SIPEN/VEP/RJ (1997 a 2006).

\section{Anexo 12}

Tabela 11. Tráfico Internacional segundo Nacionalidade do apenado condenado por Tráfico

\begin{tabular}{|c|c|c|c|c|c|}
\hline \multirow[b]{2}{*}{ Tráfico Internacional } & & \multicolumn{3}{|c|}{ Nacionalidade } & \multirow[b]{2}{*}{ Total } \\
\hline & & Brasileiro & $\begin{array}{l}\text { Estrangeiro } \\
\text { não-africano }\end{array}$ & Africano & \\
\hline \multicolumn{6}{|l|}{ Outros crimes de } \\
\hline \multirow[t]{2}{*}{ Tráfico } & Freq & 14580 & 31 & 9 & 14620 \\
\hline & $\%$ Nacion. & 98,9 & 15,2 & 7,7 & 97,1 \\
\hline \multirow[t]{2}{*}{ Tráfico Internacional } & Freq & 157 & 173 & 108 & 438 \\
\hline & $\%$ Nacion. & 1,1 & 84,8 & 92,3 & 2,9 \\
\hline \multirow[t]{2}{*}{ Total } & Freq & 14737 & 204 & 117 & 15058 \\
\hline & $\%$ Nacion. & 100,0 & 100,0 & 100,0 & 100,0 \\
\hline
\end{tabular}

Fonte: SIPEN/VEP/RJ (1997 a 2006). 
Anexo 13

Tabela 12. Resumo dos Resultados do Perfil dos Apenados

\begin{tabular}{cccc}
\hline Perfil & Brasileiro & $\begin{array}{c}\text { Estrangeiro } \\
\text { não-africano }\end{array}$ & Africano \\
\hline \% de homens & 94,1 & 82,9 & 77,3 \\
\hline Idade média & 26,4 & 36,6 & 31,9 \\
\hline \% Sem instrução ou Fundamental & 93,2 & 47,8 & 44,1 \\
\hline \% Ensino Superior & 1,1 & 14,1 & 17,8 \\
\hline \% Solteiros & 87,6 & 60,9 & 65,0 \\
\hline Cor & & & \\
\hline \% Brancos & 36,4 & 85,4 & 7,1 \\
\hline \% Pardos & 38,1 & 12,6 & 9,5 \\
\hline \% Pretos & 25,5 & 2,0 & 83,3 \\
\hline Tipo de Crime & & & 85,4 \\
\hline \% Tráfico & 29,7 & 64,4 & 2,9 \\
\hline \% Roubo & 49,7 & 3,2 & 4,4 \\
\hline \% Furto & 13,1 & 26,5 & 70,1 \\
\hline Tráfico Internacional & & & 92,3 \\
\hline \% sobre apenados & 0,2 & 43,6 & \\
\hline
\end{tabular}

